\title{
Gene and other biological therapies for vascular diseases
}

\author{
D Stephan ${ }^{1,2}$, EG Nabel ${ }^{2}$ \\ 'Service d'Hypertension et des Maladies Vasculaires, Institut de Pharmacologie et de Médecine Experimentale, \\ Faculté de Médecine. CHRU Strasbourg. Strasbourg 67000 France; \\ 2 Department of Internal Medicine and Physiology, Cardiovascular Research Center. \\ University of Michigan, Ann Arbor, MI, USA
}

(Received 9 September 1996; accepted 25 October 1996)

\begin{abstract}
Summary - Gene transfer and antisense therapy offer novel approaches to the study and treatment of vascular diseases. The localized nature of vascular diseases like restenosis has made the application of genetic material an attractive therapeutic option. Viral and nonviral vectors have been developed to facilitate the entry of foreign DNA or RNA into cells. Vector improvement and production, demonstration of vector safety and demonstration of therapeutic efficacy are among the main present challenges. Various strategies have already been shown to be successful in preventing restenosis in animal models and include: the transfer of the herpes simplex virus thymidine kinase associated with ganciclovir; transfection of the cell cycle regulatory genes encoding for the active form of retinoblastoma gene product $(\mathbf{R b})$ or the cyclin-dependant kinase inhibitor $\mathbf{2 1}$, and antisense therapy. Therapeutic angiogenesis using gene transfer is a new strategy for the treatment of severe limb ischemia. Transfection of DNA encoding for the vascular endothelial growth factor has resulted in increasing collateral flow in animal models of peripheral ischemia. This approach is currently being investigated in a clinical trial in patients with distal ischemia. Other potential targets for genetic treatment in cardiovascular diseases include thrombosis, extracellular matrix synthesis and lipid metabolism.
\end{abstract}

gene transfer / gene expression / gene vectors / antisense oligonucleotides / restenosis / angiogenesis

\section{INTRODUCTION}

Gene transfer and antisense therapy offer novel approaches to the study and treatment of vascular diseases. Initially designed to correct inherited disease, gene therapy has found new applications in the field of vascular pathologies. The localized nature of major vascular diseases like coronary artery restenosis after angioplasty has made the limited application of genetic material an attractive therapeutic option. Thus, smooth muscle cell proliferation, a major mechanism involved in the coronary restenosis, can be prevented by gene or antisense therapy in animal models. In peripheral arterial diseases, therapeutic angiogenesis by gene transfer is an alternative approach for the treatment of critical limb ischemia. Numerous pharmacological approaches, including antiplatelet agents, anticoagulants, angiotensin-converting enzyme antagonists and cytotoxic drugs, have failed to inhibit restenosis. In vascular peripheral diseases, there is inadequate evidence to support the routine use of primary pharmacological treatment in patients with critical leg ischemia. Thus, gene therapy may offer pharmacodynamic and pharmacokinetic advantages compared to conventional therapy such as specific distibution of the drug (gene) to the site of the disease by delivery systems or tissue specific promoters and long lasting effect, with the gene product being synthesized as long as the gene is expressed in the transfected cells.

\section{TRANSFER OF NUCLEOTIDS INTO THE VASCULAR WALL}

One of the main challenges in gene transfer is the introduction of nucleotides into the host cells. Hence, methods have been developed to transfer foreign DNA or RNA into cells. Viral and nonviral vectors have been employed in vascular gene transfer studies to overcome the natural resistance of vascular cells to foreign nucleotides, thus facilitating 
the delivery and entry of the recombinant genetic material into these cells. Vectors include viral vectors, such as retrovirus and adenovirus, and nonviral vectors, such as cationic liposomes, liposome viral conjugates, polycations and polymer gels.

\section{Viral vectors}

Viruses have received considerable attention as DNA carriers because of their efficient infection of host cells. Several types of viruses, including retroviruses and adenoviruses, are used for gene delivery.

\section{Retroviruses}

Retroviruses are efficient vectors in eukaryotic cells for several reasons. The retrovirus life cycle involves several steps that facilitate the uptake and expression of foreign genes in the host cells, including reverse transcription of the viral RNA, integration of the complementary DNA into the host genome and expression of the viral genes by the infected cell. This ability of the retrovirus vector to become part of the host genome could be hazardous for the host cells if the production of the virus is not controlled. Retroviruses are thus rendered replication incompetent by removal of the structural genes necessary for replication. Synthesis of the viral particles is accomplished using a packaging cell line that contains the missing genes for replication. Virus stock is used to infect host cells, resulting in integration of viral genome and stable gene expression of the new gene.

Retrovirus-mediated gene transfer has been used for cell-mediated gene transfer into endothelial cells (Dichek et al, 1989; Nabel et al, 1989; Wilson et al, 1989; Conte et al, 1994) and hepatocytes (Grossman et al, 1994) and direct gene transfer in pig arteries (Nabel et al, 1990; 1992). Despite the relative ease with which stable retroviral infection is accomplished in many cell types, the efficiency of gene transfer in vascular cells via retroviral vectors is relatively low. Approximately 5 to $10 \%$ of rat, porcine or bovine endothelial cells have been infected in vitro, while 0.1 to $1 \%$ of endothelial cells have been infected in vivo (Nabel et al, 1990; Leclerc et al, 1992). In addition, retroviral vectors are only effective in replicating cells, thus limiting the using of this vector in quiescent vascular cells.

The safety concerns regarding gene transfer when using retroviral vectors is dominated by the risk of mutations linked to the integration of a foreign DNA into the host cell genome, particularly when using retroviruses with viral oncogenes. In a preclinical animal study, three of eight immunosuppressed monkeys developed a T cell lymphoma 6 months following gene transfer in bone marrow stem cells using a retroviral vector. The lymphoma was the result of a contamination of the vector stock by a wild-type virus (Kolberg, 1992). In contrast, 5 month studies of porcine serum and peripheral blood lymphocytes derived from direct retroviral gene transfer studies in porcine arteries have revealed no wild-type recombination (Nabel et al, 1990).

In summary, retroviral vectors are low efficiency vectors in vascular cells in vivo. Integration into the host genome results in stable gene expression over a period of months (Nabel et al, 1990). Because retroviral vectors infect replicating cells, application to quiescent cells is limited. Finally, the safety of direct gene transfer in vivo using retroviral vectors has not been completely determined.

\section{Adenoviruses}

In order to develop more efficient vectors for vascular gene transfer, many investigators have employed replication-defective adenoviral vectors. Recombinant adenoviruses have several properties that make them attractive vectors for in vivo gene delivery, including infectivity for numerous cell types, high transfection efficiency and absence of mutagenicity. However, several issues relevant to application to human therapies, including stability of gene expression, host cell immune response, transmission to germline cells and toxicity, have not been systematically studied.

The human adenovirus is a nonenveloped, icosahedral, double-stranded DNA virus of $37 \mathrm{~Kb}$ (reviewed in Horwitz, 1991). There exist more than 100 different serotypes of adenovirus in mammalian species and 49 in humans. Adenoviruses infect a broad range of mammalian cells by attachment to a cell surface glycoprotein receptor through the fibrous component of its capsid. The mechanism by which the adenovinus enters a cell is not completely known and presumably occurs via receptor-mediated endocytosis. The viral genome escapes lysosomal degradation due to a terminal protein covalently linked to the terminal regions of the genome. Following release from the cytoplasm, the viral genome translocates to the nucleus but is not integrated in the host genome. It remains in the nucleus as an episome. Extrachromosomal location of the virus greatly reduces the chances of mutation by random integration and dysregulation of important host regulatory genes.

Adenovinuses type 2 and 5 are currently used for 
gene therapy. Adenoviral vectors are constructed by insertion of foreign genes into one of three locations, replacing the early regions 1 or 3 (E1 or E3), or as an insertion between the E4 region and the end of the genome (reviewed in Horwitz, 1991; Gerard and Meidel, 1993; Kozarsky and Wilson, 1993). The El region is required for adenoviral replication, and replacement of the El region with the gene of interest results in a replication-defective virus. A recombinant replication-incompetent adenovins is produced with a helper cell line. An adenoviral plasmid encoding cDNA of interest and containing an El deletion is co-transfected with remaining regions of adenovirus genome in 293 cells, a human embryonic cell line genetically modified to express El. Homologous recombination between the two DNAs generates a packaged recombinant viral genome. Recombinant adenoviruses can be generated in very high titer, often $>10^{9}$ plaque-forming units ( $\mathrm{pfu}$ ) per $\mathrm{mL}$. The resulting virus is capable of infecting many cell types and can express the introduced gene but can not replicate in a cell that does not express the E1 gene.

Adenovinus vectors have been used for in vitro transfection studies in human umbilical vein endothelial cells (Lemarchand et al, 1992) and cardiomyocytes (Kass-Eisler et al, 1993) with a high rate of gene transfer. In vivo adenovirus-mediated gene transfer has been performed in carotid and jugular veins (Lemarchand et al, 1993), rat myocardium (Kass-Eisler et al, 1993), rabbit peripheral arteries (Steg et al, 1994; Feldman et al, 1995; Simari et al, 1996) and ex vivo in saphenous veins (Chen et al, 1994). Several adenovirus-mediated gene therapy strategies aiming to reduce cell proliferation have been conducted successfully in the vessel wall, including transfer of the herpes simplex virus thymidine kinase gene (Ohno et al, 1994; Chang et al, 1995b; Simari et al, 1996), a nonphosphorylated form of retinoblastoma (Rb) gene (Chang et al, 1995b), and the inhibitory cell cycle protein p21 (Chang et al, 1996; Yang et al, 1996).

Main limitations of adenovirus-mediated gene transfer include immunogenicity and cell toxicity. Adenoviral infection of experimental animals can result in humoral and cellular immune responses to the vector and vector-infected host cells (Wilson, 1996). Adenoviruses as gene-delivery vehicles can lead to the synthesis of neutralizing antibodies directed against viral capsid proteins as well as the expressed foreign gene which may decrease the amount and length of gene expression and hamper a second administration (Kass-Eisler et al, 1994). The duration of the gene expression in several ani- mal models appears to be limited to 3 or 4 weeks (Lemarchand et al, 1993; Steg et al, 1994). In addition, limited gene expression may be due to loss of genome or extinction of the promoter.

Administration of wild-type replication-competent adenoviruses have been associated with inflammatory phenomena in the lung and the liver in animal models (Herz and Gerard, 1993; Prince et al, 1993). In balloon-injured rat carotid arteries, dose-response studies of adenovirus efficacy and toxicity have shown that maximum recombinant gene expression was produced by virus concentrations ranging from $2 \times 10^{10}$ to $5 \times 10^{10} \mathrm{pfu} / \mathrm{mL}$, without significant toxic effects on the arterial wall. Infusion of the adenovirus at high titers $\left(10^{\prime \prime} \mathrm{pfu} / \mathrm{mL}\right)$ resulted in decreased gene expression and local toxicity (Schulick et al, 1995). In a rabbit model of gene transfer into normal arteries, exposure to adenovirus vectors $\left(2 \times 10^{10} \mathrm{pfu} / \mathrm{mL}\right)$ resulted in a pronounced infiltration of $T$ cells throughout the arterial wall, an upregulation of intracellular adhesion molecule-1 and vascular cell adhesion molecule-1 in arterial smooth muscle cells and a neointimal hyperplasia (Newman et al, 1995). Several mechanisms are proposed for the adenovirus toxicity: the expression of a viral protein, like the E4 product, can induce cytopathic effects; the host immune reponse directed toward the virus leads to inflammation; infection of cells at high level of multiplicity of infection can induce toxicity (the cell toxicity of the viral capsid, basepenton, is demonstrated in vitro).

An additional disadvantage is size limitation. DNA inserts larger than $10 \%$ of the viral genome size may not be packaged by the virus. In practice, adenoviral vectors encoding nucleotide sequences longer than $3.5 \mathrm{~Kb}$ are difficult to construct (Gerard and Meidel, 1993).

First generation recombinant adenovirus vectors, utilizing a deletion of E1 genes and partial deletion of E3 gene have been useful for in vivo applications of gene transfer. However, gene expression has been transient and associated with immunogenicity best characterized in the mouse, and lung inflammation in human studies. In an attempt to limit these side effects, new strategies of cloning have been used. The E2 region of the adenovirus genome appears to be involved in stimulating the immune response as well as promoting a local inflammatory process. Adenoviruses in which the E2A gene has been mutated induce less inflammatory response and are associated with longer gene expression in the mouse lung and liver (Engelhardt et al, 1994; Yang et al, 1994). 


\section{Nonviral vectors}

Nonviral vectors have been developed over the past several years in an effort to reduce the potential risks of viral-mediated gene transfer, particularly for human application. Effective nonviral vectors include liposomes, calcium phosphate, electroporation, DEAE-dextran and polycations.

\section{Liposomes}

Liposomes are self-assembled colloidal particles in which a lipid bilayer encapsulates some of the surrounding aqueous medium (Lasic and Papahadjopoulos, 1995). Since their original description, liposomes have been discussed as vehicles that could be used as carriers of pharmaceutically active agents. However, their medical utility appeared to be limited by their rapid uptake by phagocytic cells of the immune system, predominantly in the liver and spleen (Lasic and Papahadjopoulos, 1995). Interest in liposomes was rejuvenated by their ability to deliver nucleic acids into cells. Thus, liposomes were capable of encapsulating DNA, then fusing with the cell membrane and delivering the polynucleotides into the cytoplasm (Felgner, 1990). Although liposome-mediated transfection methodology is notable for its simplicity, several technical difficulties slowed the development of this technology, including the poor efficiency of conventional liposomes to package DNA (size limitation) and extensive lysosomal degradation of the liposome and the encapsulated polynucleotide (Felgner, 1990). In the late 1980s, cationic liposomes were developed in order to overcome some of these deficiencies. Cationic liposomes have been employed to deliver DNA, RNA and antisense oligonucleotides to a variety of cells (Felgner et al, 1987). The rationale for synthesis of cationic liposomes and their use as polynucleotide delivery agents stems from the observation that DNA and all biological surfaces, including cell membranes, are negatively charged (nucleic acids) or have a relatively negative charge (biological surfaces) (Felgner, 1990). In the DNA-cationic liposome complex, the nucleic acids are not encapsuled but are simply complexed with small unilamellar vesicles by electrostatic interaction (Felgner et al, 1987). The supramacromolecule then interacts spontaneously with the negatively charged cell membrane and delivers the nucleic acids into the membrane. Although the interactions between the lipid-DNA complex and the cell membrane are not completely understood, the process yields efficient transfection of many of the cells and tissues.

Cationic liposome reagents are a growing class of compounds that are useful for the transfection of cells in vitro and for gene delivery in vivo. The prototype cationic lipid, DOTMA, mixed with a neutral lipid DOPE, is commercially available as Lipofectin (GIBCO-BRL, Gaithersburg, MD, USA) (Felgner and Ringold, 1989). Improvements have reduced toxicity and increased transfection efficiency. Examples of second generation cationic liposomes include DOSPADOOPE, commercially available as Lipofectamine ${ }^{\oplus}$ (GIBCO-BRL).

The interactions between the cationic liposomeDNA complex and the cell membrane are based on electrovalent interactions. The molar ratio between the DNA and the cationic liposome is therefore a critical parameter for the reagent's efficacy (Felgner and Ringold, 1989). Theoretically, the optimal ratio should be such that the amount of positive charge contributed to the cationic liposome slighty exceeds the number of negative charges on the DNA, so that the complexes have a net positive charge to facilitate their interaction with the negatively charged target cell surface (Felgner and Ringold, 1989; Stephan et al, 1996). In practice, differences in target cell, plasmid DNA and liposome preparations require adjustments of the lipid to DNA ratio and absolute concentrations to optimize transfection efficiency (Stewart et al, 1992; San et al, 1993; Stephan et al, 1996).

Cationic liposomes have been employed in animal models of vascular diseases, including peripheral arteries in the pig (Nabel et al, 1990, 1992a, $1993 a, b, c)$ and coronary vasculature (French et al, 1994; Shi et al, 1994). Like retroviral vectors, however, cationic liposomes are low efficiency vectors in vascular cells (Nabel et al, 1990). In addition, the duration of expression seems to be limited to 4 weeks (Nabel et al, 1990). Further modifications to the chemical formulation of cationic liposomes appear promising in terms of improving transfection efficiency. A major advantage of cationic liposomes is safety. In studies of direct gene transfer mediated by cationic liposomes, gene expression was limited to the site of gene introduction, and organ toxicity (including the gonads) as well as biochemical and hematologic changes, have not been observed (Stewart et al, 1992; San et al, 1993; Stephan et al, 1996). Table I summarizes the characteristics of viral and liposomal gene vectors.

\section{Polycations}

Several polycations such as lipopolyamines (dioctadecylamidoglycylspermine [DOGS], commercially available as Transfectam ${ }^{\circledR}$ ), polyamidoamine polymers and polyethylenimine are efficient trans- 
Table I. Catheter-based gene delivery vectors.

\begin{tabular}{lcccc}
\hline & $\begin{array}{c}\text { Effic- } \\
\text { iency }\end{array}$ & $\begin{array}{c}\text { Inte- } \\
\text { gration }\end{array}$ & Stability & Toxicity \\
\hline $\begin{array}{l}\text { Viral } \\
\text { Retrovirus } \\
\text { Adenovirus }\end{array}$ & $\begin{array}{c}\text { Low } \\
\text { High }\end{array}$ & $\begin{array}{c}\text { High } \\
\text { Low }\end{array}$ & $\begin{array}{c}\text { Months } \\
\text {-4 weeks }\end{array}$ & $\begin{array}{c}\text { Minimal } \\
\text { Immuno- } \\
\text { genicity } \\
\text { Inflammation }\end{array}$ \\
$\begin{array}{l}\text { Non viral } \\
\text { Liposomes }\end{array}$ & $\begin{array}{c}\text { Low- } \\
\text { moderate }\end{array}$ & Low & $3-4$ weeks & Minimal \\
\hline
\end{tabular}

fection agents. Although quite different in chemical structures, these polycations possess substantial buffering capacity below physiological $\mathrm{pH}$. This property may permit endosome buffering and thus prevent DNA from lysosomal degradation. Polycations are attractive nonviral vectors for in vitro and in vivo gene transfer (Boussif et al, 1995).

\section{Liposome viral conjugates}

A recent strategy to transfer nucleotides into the vascular wall uses both liposome and viral technologies. Liposomes that have encapsulated polynucleotides are coated with viral membrane protein in order to increase the rate of transfection by using the property of viruses to bind cell membranes. Purified hemaglutinating viruses of Japan (HVJ), inactivated by either heat or ultraviolet irradiation, are used to fuse DNA-loaded liposome vesicles with cell membranes. This method yields an efficiency of $\geq 30 \%$ of vascular cells transfected without local toxicity. HVJ liposome-mediated gene transfer has been used to transfect angiotensin-converting enzymes and renin genes in vascular smooth muscle cells in vitro (Morishita et al, 1993a), nitric oxide synthase gene (Leyden et al, 1995) or antisense oligonucleotides into rat carotid arteries (Morishita et al, 1993a; 1994).

\section{Polymer gels}

Arterial gene transfer has been perfomed during balloon angioplasty by delivery of naked DNA from a thin coat of hydrogel polymer applied to a standard angioplasty balloon. This method applied in rabbit arteries in vivo resulted in a $\leq 0.1 \%$ frequency of transfected cells. Gene expression in cells was observed mainly in intima or subintima (Riessen et al, 1993). Pluronic gel has been employed to deliver antisense oligonucleotide to the external and internal surfaces of the arteries (Simons et al, 1992; Bennet and Schwartz, 1995).

\section{CELL-MEDIATED VERSUS DIRECT GENE TRANSFER}

Two strategies are currently employed to introduce foreign genes into vascular cells: cell-mediated and direct gene transfer. Cell-mediated or ex vivo gene transfer is a multistep process in which autologous endothelial or smooth muscle cells are grown from an artery or a vein. The cells are transfected with a vector expressing the recombinant gene. The genetically modified cells are then reimplanted onto the target vascular segment in the host. The advantage of cell-mediated gene transfer is that gene transfer can be perfomed in a specific cell type, for example, endothelial or smooth muscle cells. Disadvantages of this technique include the requirement for syngeneic cell lines to prevent an immune response to the transplanted material, transfection of cells in culture and a time delay between cell harvest and implantation.

Genetically modified endothelial cells have been seeded onto denuded porcine iliac arteries (Nabel et al, 1989), rabbit arteries (Conte et al, 1994), prosthetic vascular grafts (Wilson et al, 1989) and reimplanted in vivo on steel stents (Dichek et al, 1989). Gene expression lasted at least 4 weeks in peripheral arteries (Nabel et al, 1989) and 5 weeks in prosthetic grafts (Wilson et al, 1989).

A potential role for ex vivo vascular gene transfer may be enhancing fibrinolysis within vascular devices highly predisposed to thrombosis, such as stents and prosthetic grafts. In one study, a human t-PA gene was transfected into sheep endothelial cells which were then seeded onto stainless steel stents. Endothelial cells replicated, covering the stents. Secretion of t-PA was demonstrated from cells before and after the transduced cells were implanted onto the stent (Dichek et al, 1989). Genetically modified smooth muscle cells expressing human adenosine deaminase have been seeded onto rat carotid arteries, inducing a local production of the recombinant protein (Lynch et al, 1992).

The direct introduction of nucleotides into vascular cells, in situ, is a compelling modality for several reasons (Nabel and Nabel, 1994). Direct gene transfer is less complex and requires less sophisticated technology compared with cell-mediated gene transfer. Direct gene transfer is less disruptive to the normal architecture of the vessel, for example, endothelial denudation is not performed prior transfection. Historically, the feasibility and specificity of direct gene transfer was demonstrated using a recombinant nonreplicative retrovirus expressing a reporter gene, beta-galactosidase, 
in pig arteries (Nabel et al, 1990). Since then, direct gene transfer has been achieved in normal, injured and atherosclerotic arteries using recombinant adenoviruses or liposomes (Nabel et al, 1990; Simari et al, 1996).

\section{DELIVERY SYSTEMS}

Interest in gene therapy for vascular disease is generated by the localized nature of the disease, rendering these lesions accessible to direct gene infusion via catheters. Intravascular catheters have been developed and modified to fit the different anatomical locations allowing gene delivery in various situations. For instance, coronary arteries cannot be occluded for a long time, and special devices allowing continuous perfusion downstream of the lesion are being developed. Currently, several local drug delivery catheters have been evaluated in animal models, including a double balloon catheter, a standard porous balloon catheter, a hydrogel-coated catheter and a channel balloon catheter. The double balloon catheter consists of two independently inflatable balloons located proximal and distal to the connecting shaft, which permits infusion of catheter contents. Inflation of the balloons creates a central infusion chamber for gene transfer (fig 1). Genetic material has been successfully delivered into peripheral arteries using this catheter (Nabel et al, 1989, 1990, 1992a, b, 1993a, b, c; San et al, 1993; Ohno et al, 1994; Steg et al, 1994; Chang et al, 1995a).

Catheters containing pores on the surface of the balloons have been developed to deliver solutions locally to sites with lesions. Instillation of solutions under pressure is performed through these pores into the arterial wall. Transfer of genes has resulted in variable gene expression associated with vascular injury in the arterial wall. Focal jet sprays may form at the site of the pores, creating areas of intimal disruption, medial dissection and subintimal haemorrhage.

The hydrogel catheter is a standard angioplasty catheter covered with a hydrogel coating that acts to absorb hydrophilic agents (Riessen et al, 1993; Steg et al, 1994; Isner et al, 1995). Polynucleotides are applied to the gel-coated balloon. When the balloon is inflated in an artery, the nucleotide is pressed into the arterial wall. One disadvantage of the hydrogel catheter is that the nucleotide can be rapidly washed off the balloon after exposure to the bloodstream, so protective sheaths may be required during the transport in the arterial circulation.
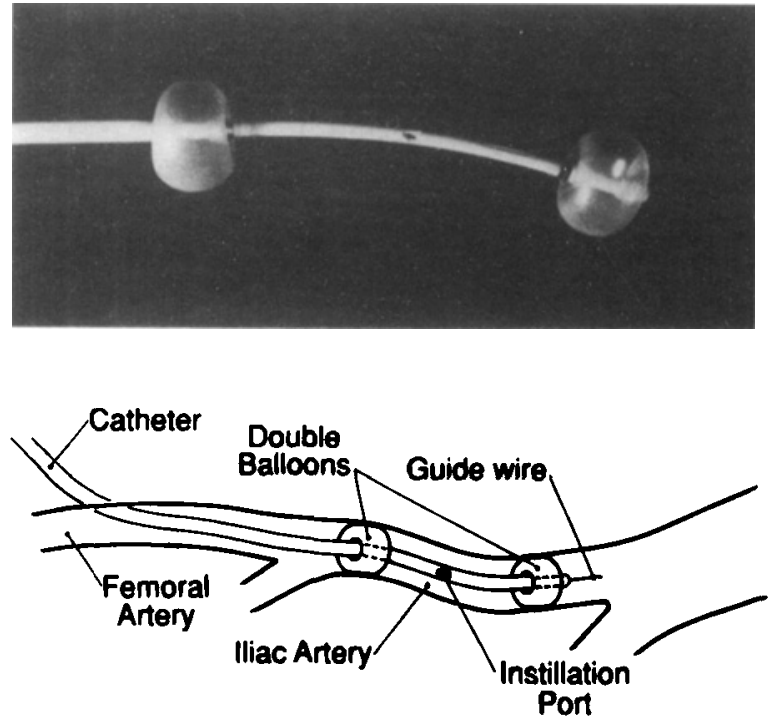

Fig 1. Method of introduction of a recombinant gene. A double catheter is inserted into an artery. Inflation of a proximal and a distal balloon creates a central protected space into which the modified cells or vectors can be directly instilled. Vascular cells in adjacent area are transfected to express the recombinant gene (Reprinted with permission from Nabel et al [1989]; copyright 1996, American Association for the Advancement of Science).

The channel balloon catheter contains multiple external channels circumferentially arranged around an angioplasty balloon. The inflation pressure necessary to inflate the balloon is separated from the hydrostatic pressure needed to infuse nucleotides. The channels, containing pores, are placed against the arterial wall by inflation of the inner balloon and thereafter, intramural delivery can occur independently through the pores (Feldman et al, 1995).

\section{GENE TRANSFER AND ANTISENSE APPROACHES TO THE TREATMENT OF VASCULAR DISEASES}

\section{Vascular proliferation: the restenosis paradigm}

Percutaneous transluminal coronary angioplasty (PTCA) remains a mainstay of therapy for symptomatic coronary artery disease (Landau et al, 1994). While this procedure is initially successful in relieving critical arterial stenoses in more than $90 \%$ of patients, a reactive smooth muscle cell (SMC) proliferation ensues within the first 6 months after the procedure, leading to clinically significant intimal hyperplasia in 30 to $50 \%$ of the treated arteries 
(Schwartz et al, 1992). The pathophysiology of restenosis is complex and multiple factors contribute, including thrombus formation, smooth muscle cell proliferation and extracellular matrix synthesis and recoil of the vessel wall (Nabel et al, 1994). Recent findings have suggested that restenosis may be related, at least in part, to reactive-adaptative remodeling processes including those by which blood vessels tend to compensate for plaque formation (including artery enlargement as plaques form), thereby preserving lumen cross-section area for an extended period (Glagov et al, 1987). Disruptions, introduced by angioplasty, result in local and focal redistributions of both wall shear stress and mural tensile stress and elicit adaptative modeling reactions in intima, media and plaque. These changes will appear as alterations of lumen configuration, lumen radius and overall artery size. Regulation of this response is closely related to the interaction between local circulatory stimuli and the tissue responses which tend to maintain or restore baseline flow conditions (Glagov, 1994). Two studies have shown that a mechanical prevention of remodeling by coronary stent placement could reduce reactive-adaptative processes following PTCA (Sernuys et al, 1994; Fischman et al, 1994).

Intimal hyperplasia following PTCA is most likely an exaggerated form of the response to arterial injury commonly seen in vascular proliferative diseases including atherosclerosis (Ross, 1993). Numerous pharmacologic approaches, including antiplatelet agents, anticoagulants, angiotensinconverting enzyme antagonists and cytotoxic drugs, have failed to inhibit restenosis (Thornton et al, 1984; Ellis et al, 1989; Muller et al, 1991; MERCATOR Study Group, 1992). Stents have reduced the clinical incidence of coronary artery restenosis and the role of cellular proliferation in restenosis of stents is under investigation. The localized nature of restenosis has made the local application of highly concentrated pharmacological agents or genetic material an attractive therapeutic option. Local delivery of pharmaceutical compounds again was not successful, mainly because of the short term of retention in the vessel wall. More recently, genetic approaches have been used both to better understand the molecular mechanisms underlying the SMC proliferative response to arterial injury and to form the basis for novel gene-based therapies for restenosis and other vascular proliferative diseases (Nabel et al, 1993c; Ohno et al, 1994; Chang et al, 1995b; Chang et al, 1996). Furthermore, gene transfer of vectors which are taken up by the targeted cells provide prolonged local expression of their gene product.
Animal models of restenosis

Intimal cell proliferation is an important pathophysiological event in the restenosis process. It is moreover an accessible target for antiproliferative gene therapy. Animal models have been designed to reproduce human atherosclerotic lesions. However, there are significant differences between the models and their fidelity to human vascular lesions. Three animal species, the rat, the rabbit and the pig, are commonly used in restenosis studies. Results among these species have been shown to differ significantly, raising issues of suitability of animal models for human restenosis.

The rat carotid model has been widely used (Lynch et al, 1992; Simons et al, 1992; Bennet et al, 1993; Morishita et al, 1993a: Morishita et al, 1994; Chang et al, 1995b; Leyden et al, 1995; Nakajima et al, 1995; Schulick et al, 1995; Villa et al, 1995; Rade et al, 1996; Chang et al, 1996). An endothelial denudation of the common carotid artery is performed with a Fogarty balloon catheter. The balloon catheter is introduced into the external carotid artery and passed several times with the balloon distended sufficiently with air to generate slight resistance and remove the endothelium. This endothelium denudation induces a strong neointimal SMC proliferation with matrix production. In this model, SMC migration and proliferation is a major feature of the development of intimal thickening. It appears that the rate of SMC proliferation in this model exceeds SMC proliferation in human lesions. Pharmacological therapies which effectively inhibited intimal SMC proliferation in this model were not successful in human restenosis, raising questions about extrapolation of results obtained in the rat carotid artery to human vascular diseases. For example, the gene transfer of type 2 angiotensin II receptors increases neointimal formation in the injured rat carotid model (Nakajima et al, 1995). Conversely in the same model, antagonists of type 2 angiotensin receptors prevents the neotintimal thickening after injury, but fails to demonstrate the same effect in the pig coronary artery (Huckle et al, 1996). Thus, several reports have demonstrated the ability of angiotensin-converting inhibitors to block the neotintima formation in the rat but attemps to duplicate these results, namely in human restenosis, have failed (MERCATOR Group, 1992). Finally, an additional limitation of this model is the difficulty to develop atherosclerotic lesions in the rat.

Catheter-mediated arterial injury and cholesterol feeding in rabbits result in the development of atherosclerotic lesions characterized by foam cells, inflammatory infiltrates and intimal cell 
proliferation (Leclerc et al, 1992; Conte et al, 1994: Steg et al, 1994; Takeshita et al, 1994; Newman et al, 1995; Feldman et al, 1995; Simari et al, 1996). An atherosclerotic lesion is created by endothelial denudation using a Fogarty catheter combined with a high cholesterol diet. Several weeks after the first injury a balloon angioplasty is performed at the same site. Continual intimal thickening follows and treatments can be tested on the developing lesion. An advantage of this model is that arterial lesions with foam cell infiltration develop within 3 weeks of cholesterol feeding; however, morphological features of these lesions do not mimic human arteriosclerosis. The lipid content of these plaques is significantly higher than in human plaques. This particular aspect of the atherosclerosis induced in rabbits may explain the efficacy of lipid-lowering drugs in this model (Gellman et al, 1991). These drugs failed to demonstrate the same effect in the human coronary restenosis (Sahni et al, 1991). Several strategies have been studied in this rabbit model, including the gene transfer of the herpes virus thymidine kinase (Simari et al, 1996).

In the pig, normal and balloon-injured iliac arteries (Nabel et al, 1989, 1990, 1992a, b, 1993a, b, c; Stewart et al, 1992; San et al, 1993; Ohno et al, 1994: Chang et al, 1995b) and cononary arteries (French et al, 1994; Shi et al, 1994) have been used as a model of restenosis. Pig arteries are suitable models of human vascular diseases (Ohno et al, 1994). Limitations to studies in pigs include the cost and housing of the animals and the length of time (12 to 18 months) needed to develop atherosclerotic lesions following cholesterol feeding.

Vascular gene transfer has also been employed to study mechanisms of intimal cell proliferation following expression of growth factor genes in vivo. The effects of growth factors, including platelet-derived growth factor (PDGF) (Nabel et al, 1993b), fibroblast growth factor-1 (FGF-1) (Nabel et al, 1993c) and transforming growth fac-

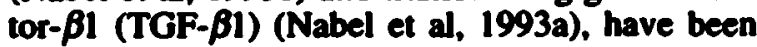
studied on the development of neointima in arteries. Recent data from human atherosclerosis specimens and gene targeting studies suggest an important role for these growth factors in human vascular disease, including atherosclerosis and restenosis (Nabel and Nabel, 1994). Liposomemediated transfection of a plasmid expression vector encoding human PDGF B, secreted FGF-1 (acidic FGF), secreted active TGF- $\beta 1$, or a reporter gene was performed into porcine iliofe- moral arteries using a double balloon catheter. Transfection of PDGF B was associated with intimal thickening, characterized by increased cellularity and smooth muscle cell proliferation, in contrast to the control artery transfected with a reporter gene (fig 2) (Nabel et al, 1993c). Transfection of a plasmid encoding a secreted form of FGF-1 was associated with intimal thickening. However, in vessels with expanded intima, neocapillaries were observed within the intima (Nabel et al, 1993a). TGF- $\beta 1$ expression was associated with a significant increase in procollagen synthesis in the intima and media that resulted in an intimal and medial thickening (Nabel et al, 1993b). These data suggest that three growth factor genes may have overlapping but distinct effects on arterial pathology and may guide the development of molecular genetic interventions to limit intimal hyperplasia following balloon injury (Nabel and Nabel, 1994).

Several gene and other biological approaches have been used successfully to prevent intimal cell proliferation in animal models, including transfer of genes encoding for herpes simplex vinus-thymidine kinase (HSV-tk) (Ohno et al, 1994; Chang et al. 1995b; Simari et al, 1996), a constitutively active form of retinoblastoma (Chang et al, 1995a), a cyclin-dependent kinase inhibitor, p21 (Chang et al, 1996; Yang et al, 1996), nitric oxide synthase (Leyden et al, 1995), a dominant negative Ras protein (Indolft et al, 1995) and recombinant hinudin (Rade et al, 1996) as well as antisense oligonucleotide therapy.

\section{HSV-dh transfer and ganciclovir trenument}

One approach to the selective elimination of dividing cells is to express a HSV-tk gene, which converts a nucleoside analog prodrug, ganciclovir, into an active toxic form in transduced cells (Borrelli et al, 1988). Incorporation of phosphorylated ganciclovir into cellular DNA induces chain termination in dividing cells, which causes cell death (Smith et al, 1982). A bystander effect, demonstrated in vascular SMC, inhibits cell growth in nontransduced cells (Ohno et al, 1994) resulting in cell killing in a greater number of cells than transfected with a HSV-ik gene. HSV. tk and ganciclovir treatment have been studied in the rat, the pig and the rabbit (normal and atherosclerotic vessels) (Ohno et al, 1994; Chang et al, 1995b; Simari et al, 1996). In these studies, adenoviral vectors encoding the HSV-tk were introduced into balloon-injured arteries at the time of the injury. Ganciclovir (25 to $50 \mathrm{mg} / \mathrm{kg}$ ) was administrated 24 to 36 hours after infection 

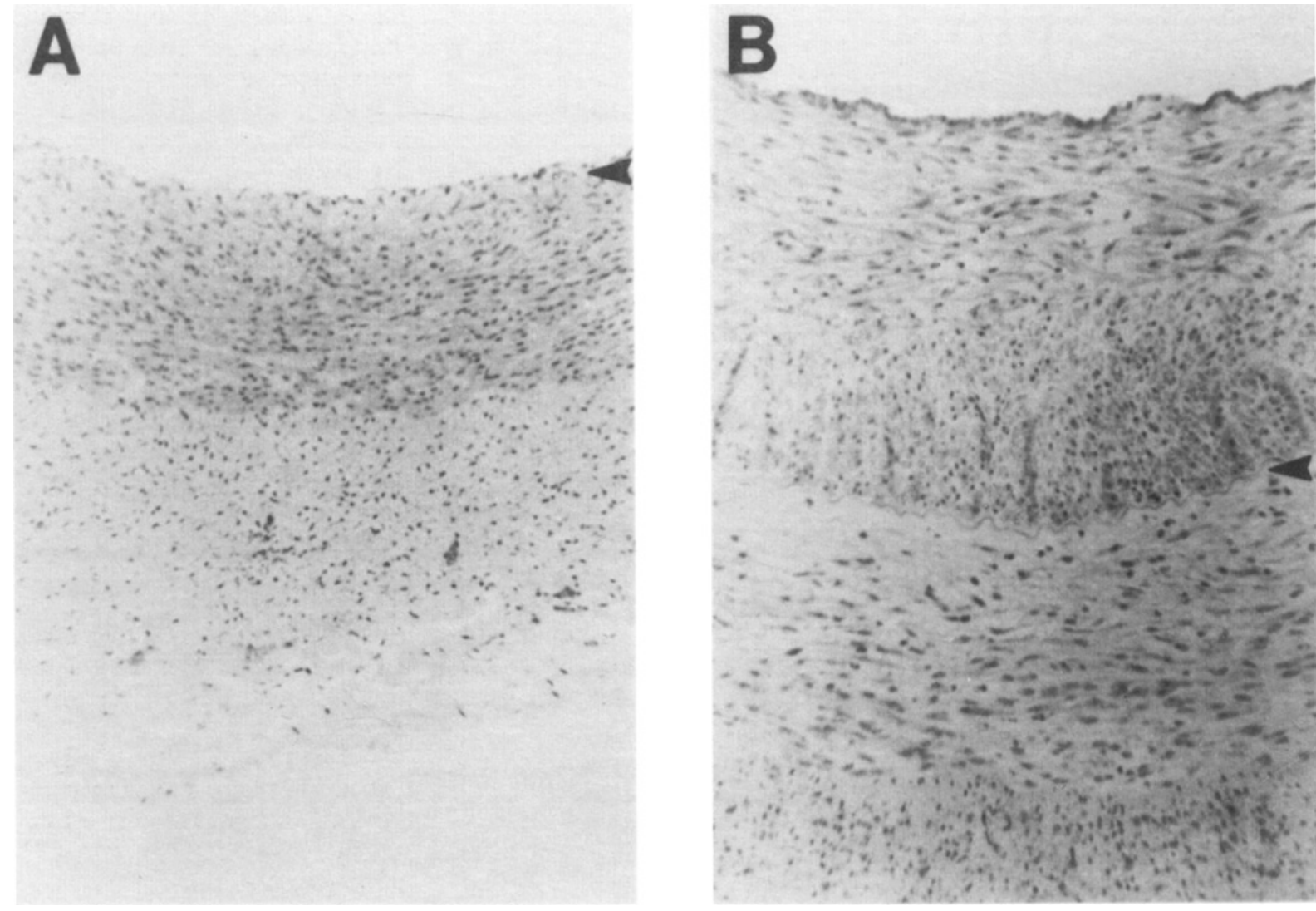

Fig 2. Expression of a recombinant growth factor gene in porcine arteries in vivo. Intimal thickening was produced following transfection of human platelet-derived growth hormone B gene into porcine iliofemoral arteries (B) compared with no intimal proliferation following transfection with a reporter gene, $E$ Coli $\beta$-galactosidase (A). The arrow denotes the intemal elastic intima (Reproduced from the J Clin Invest 1993:91:1822-9; copyright permission of the American Society for Clinical Investigation).

for 6 days. Three weeks after balloon injury and adenoviral infection, the areas of the intima and media in each arteries were measured by quantitative morphometry, and the intimal to medial (1/M) area ratio were determined. A significant reduction in the $I / M$ area ratio was observed in vessels subjected to injury in animals transduced with HSV-tk and treated with ganciclovir, compared with control animals (fig 3 ). The potential for systemic toxicity following adenoviral transfection of HSV-tk and treatment with ganciclovir was investigated by analysis of serum biochemistry and pathological examination of the main organs. None of the treated animals showed evidence of hematologic or organ toxicity. These studies demonstrate the potential utility of a molecular intervention targeted to proliferating smooth muscle cells after balloon injury. Whether this type of strategy might be effective in treating human vascular proliferative disorders awaits further confirmation.

\section{Cell cycle inhibition}

Redundancy in growth factor signaling pathways has led to the suggestion that effective therapies for vascular proliferative diseases should target nuclear cell cycle regulatory pathways rather than more proximal signal transduction molecules. The definition of cell cycle regulatory proteins has facilitated the molecular analysis of pathologic conditions related to cell proliferation. A variety of gene products originally defined in yeast have been shown to have mammalian homologs which alter activity of cyclin-dependant kinases (CDK) and regulate cell cycle progression and senescence. Two gene transfer approaches to regulation of the 


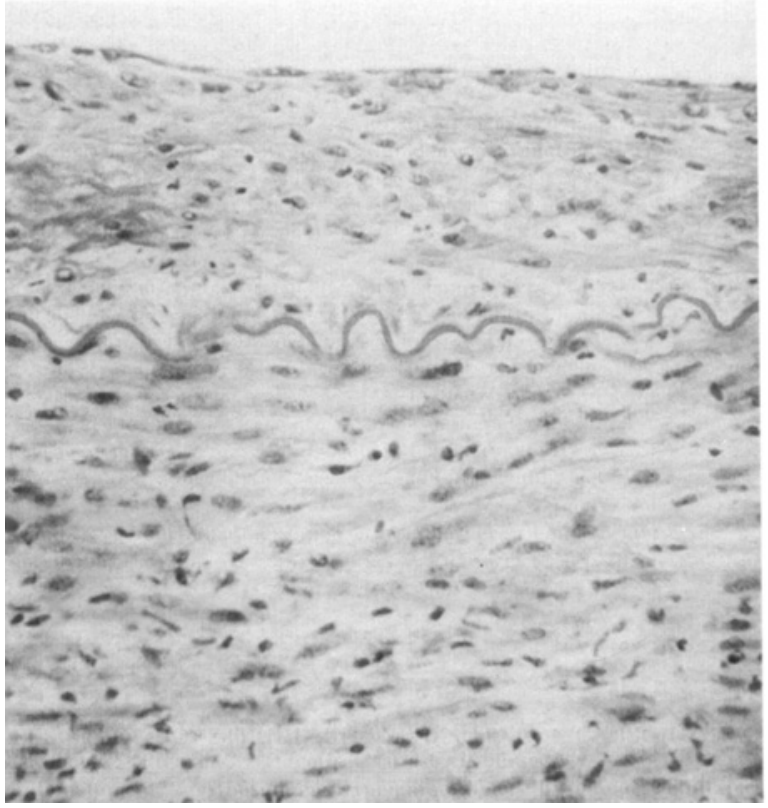

ADV-tk/-GC

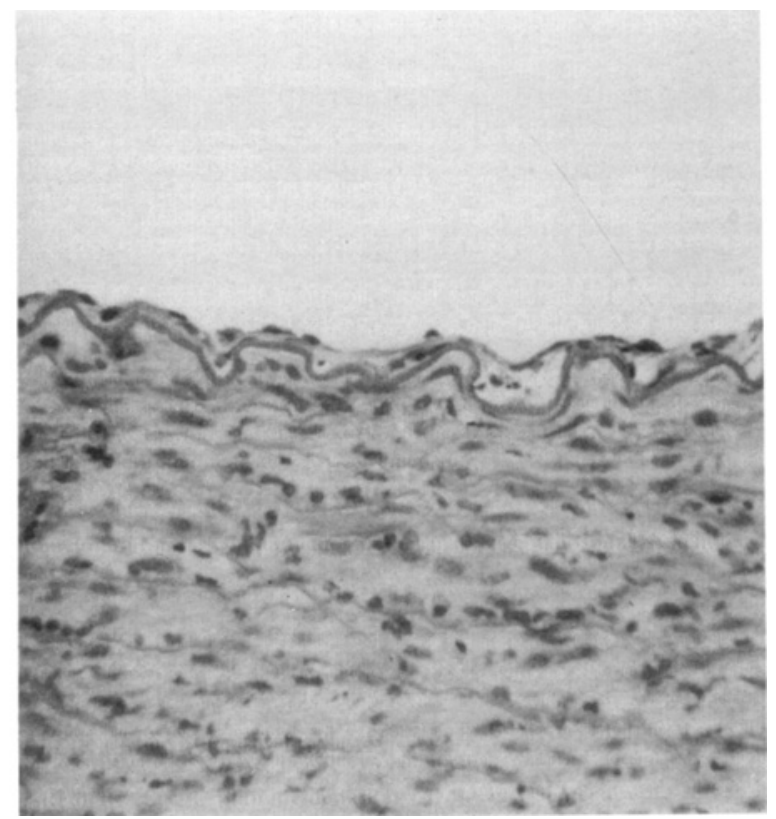

ADV-tk/+GC

Fig 3. Effect of herpes simplex virus-thymidine kinase (HSV-tk) gene expression and treatment ganciclovir (GC) on intimal and medial areas in balloon-injured arteries. Representative cross sections from iliofemoral areries of pigs injured during 1 min, then infected with adenovirus vectors encoding HSV-tk and treated with saline (left) or ganciclovir (right) (Reprinted with permission from Ohno et al [1994]; copyright 1996, American Association for the Advancement of Science).

cell cycle have been investigated in vascular models: transfer of a nonphosphorylated form of $\mathbf{R b}$ (Chang et al, 1995a) and transfer of a CDK inhibitor, p21 (Chang et al, 1996; Yang et al, 1996).

The retinoblastoma gene product $(R b)$ is present in an unphosphorylated and inactive form in quiescent arterial SMCs, but is rapidly activated by phosphorylation in response to growth factor stimulation in vitro. Localized arterial infection with a recombinant adenovirus encoding a nonphosphorylatable form (constitutively active form of $\mathbf{R b}$ ) in injured arteries significantly reduced the SMC proliferation and neointima formation in rat carotid and pig femoral arteries (Chang et al, 1995a).

P21 is a negative regulator of cell cycle progression by inhibition of CDKs required for the initiation of the $S$ phase, and by binding to and inhibiting the proliferating cell nuclear antigen (PCNA). Adenovirus-mediated overexpression of human p21 inhibits growth factor-stimulated SMC proliferation in vitro by arresting SMCs in Gl phase of the cell cycle. Localized infection of injured arteries with a p21-encoding adenovirus signifi- cantly reduced neointimal hyperplasia in the rat carotid (Chang et al, 1996) and pig iliac arteries (Yang et al, 1996).

\section{Antisense therapy}

Antisense therapy is an attractive approach for angioplasty restenosis (reviewed in Bennet and Schwartz, 1995). Several attempts to block the transcription of genes involved in cell replication have shown their efficacy in animal models of restenosis, although major concerns remain about the apparent nonspecificity of antisense oligonucleotides for their target mRNA.

Antisense approaches include oligonucleotides, antisense mRNA and autocatalytic ribozymes. Antisense oligonucleotides (ON) are short complementary DNA or RNA sequences that will hybridize to a specific mRNA forming a hybrid duplex. Two main mechanisms explain their action: 1) steric interferences to ribosome binding and translation or splice excision and 2) cleavage of mRNA by the nuclease $\mathrm{RNase} H$ which recognizes DNARNA duplexes. The advantages of antisense therapy include target specificity and ease of design 
and synthesis of oligonucleotides (ON) compared to any class of drugs. Uptake of (modified) oligonucleotides by cells is generally low and can be enhanced by complexing $\mathrm{ON}$ with liposomes or liposomes associated virus like the hemagglutinating virus of Japan (Morishita et al, 1993a; Morishita et al, 1994). Targets for antisense agents include gene products shown to be critical to cell cycle progression like c-myc (Bennet et al, 1993), c-myb (Simons et al, 1992), cdc-2 (Morishita et al, 1993a), cdk-2 (Morishita et al, 1994). One critical limitation has been the rapid degradation of $O N$ in the cell cytoplasm. Some chemical modifications have been proven to increase their stability (Wagner, 1994). Methylphosphonate, phosphorothioate, phophoroamidate or phosphotriester linkages are some of these modifications. Specificity of ONs for their targets is another major concern. ON sequences must not be too long in order to limit nonspecific binding. The shortest continuous sequence required for uniqueness of an $\mathrm{ON}$ is 12 to 15 bases. The most common size used is between 15 to $20 \mathrm{bp}$. Short hybridized sequences, which may sometimes result from nonspecific binding, can be recognized and degraded by the RNase H. A third potential complication of ON therapy is the aptamer effect. ON can bind proteins (aptamers) and alter their functions which will result in nonspecific effects on cell morphology and proliferation. The aptamer effect has been particularly demonstrated with $O N$ sequences that contain a stretch of $4 \mathrm{G}$ residues (Villa et al, 1995). Thus, the need for appropriate controls for antisense therapy has arisen. Recommended controls include not only sense, mismatched and scrambled sequences but also overexpression of the targeted mRNA or the protein to block the ON effect, measurements of mRNA and protein levels, the demonstration of a biological effect by multiple antisense sequences and the absence of biological effect for antisense ONs targeted to abundant genes not related to the one studied. Toxicity of antisense targeted to cell regulatory elements must be examined particularly in blood stem cells or other rapidly proliferating cells, like gastrointestinal cells, in case of systemic administration. Finally, the incorporation of degraded, chemically modified ON into the host genome may lead to a toxicity which has not been yet examined in detail.

\section{THERAPEUTIC ANGIOGENESIS}

It has been estimated that each year 150,000 patients require lower-limb amputations for ischemic disease in the United States. Their prognosis after amputation is even worse, and $50 \%$ of the patients will die in the 2 years following a major amputation (European Working Group on Critical Limb Ishemia, 1991). These statistics are explained in part by the lack of efficacious drug therapy. In spite of several improvements brought to these patients by new pharmacological compounds such as the prostanoids analogs, there is inadequate evidence to support the routine use of primary pharmacological treatment in patients with critical leg ischemia (European Working Group on Critical Limb Ishemia, 1991). Thus, alternative treatment strategies must be examined.

Therapeutic angiogenesis is a new strategy for the treatment of critical limb ischemia (Isner et al, 1995). Recent investigations have established the feasibility of using recombinant formulations of angiogenic growth factors to augment collateral artery development in animal models of limb ischemia (Takeshita et al, 1994; Muhlhauser et al, 1995). Overexpression of the fibroblast growth factor-1 (FGF-1) promotes intimal hyperplasia and angiogenesis in the arterial wall (Nabel et al, 1993c). The vascular endothelial growth factor (VEGF), also known as vascular permeability factor or vasculotropin is a 32 to $42 \mathrm{kDa}$ secreted glycoprotein (Connolly, 1991). VEGF has specific effects on endothelial cells (Isner et al, 1995). It is a potent mitogen and it increases cell membrane permeability. Intramuscular administration of VEGF protein induces dose-dependant collateral artery augmentation in a rabbit model of chronic limb ischemia (Takeshita et al, 1994). Human umbilical vascular endothelial cells infected with a recombinant adenovirus expressing VEGF differentiated into capillary-like structures in vitro. Neovascularisation in the tissues surrounding the site of administration, after injection of this vector into mice was also observed (Muhlhauser et al, 1995). Transfection of plasmid DNA encoding VEGF in a rabbit ischemic hind limb model using a hydrogel coated balloon catheter has resulted in stimulation of collateral flow, demonstrated by increased capillary density and increased distal blood pressure (Isner et al, 1995). In addition VEGF administation promoted the recovery of disturbed endothelium-dependent flow (Bauters et al, 1995). This approach is currently being investigated in a clinical trial in patients with severe lower extremity ischemia. In this study, the plasmid will be delivered proximal to the site of stenosis in an attempt to induce angiogenesis and relieve ischemic pain and trophic lesions (Isner et al, 1995). 


\section{FUTURE DIRECTIONS}

Recombinant genes can be expressed at local sites in arteries by gene transfer. This method permits high level and potentially long lasting local expression of recombinant proteins, and avoids systemic delivery of high concentrations of drugs which might have other systemic effects. There are a number of challenges which must be met prior to the broad application of gene or antisense therapy for cardiovascular diseases. These challenges include vector improvement and production, vector safety and therapeutic efficacy. At the present time, there are strong pre-clinical animal data suggesting a role for gene transfer in vascular cell proliferation and angiogenesis. Other potential targets for genetic treatment include thrombosis, cell adhesion, matrix synthesis and regulation of lipoprotein metabolism. These therapies could be applied to the treatment of graft occlusion, recurrent thrombosis and other vascular diseases.

\section{REFERENCES}

Barr E, Carroll J, Kalynych A et al. Efficient catheter-mediated gene transfer into the heart using replication-defective adenovirus. Gene Ther 1994;1:51-8

Bauters C. Asahara T, Lu Z et al. Recovery of disturbed endothelium-dependent flow in the collateral-perfused rabbit ischemic hindlimb after administration of vascular endothelial growth factor. Circulation 1995;91:2802-9

Bennet M. Anglin S, McEwan J, Jagoe R, Newby A, Evan G. Inhibition of vascular smooth muscle cell proliferation in vitro and in vivo by c-myc antisense oligonucleotides. J Clin Invest 1993;93:820-8

Bennet M, Schwartz S. Antisense therapy for angioplasty restenosis some critical considerations. Circulation 1995;92: 1981-93

Borrelli E, Heyman R, Hsi M, Evans R. Targeting of an inducible toxic phenotype in animal cells. Proc Natl Acad Sci USA 1988;85:7572-6

Boussif O, Lezoualc'h F. Zanta MA et al. A versatile vector for gene and oligonucleotide transfer into cells in culture and in vivo: polyethylenimine. Proc Natl Acad Sci USA 1995:92: 7297-301

Chang M, Barr E, Seltzer J et al. Cytostatic gene therapy for vascular proliferative disorders with a constituvely active form of the retinoblastoma gene product. Science 1995a; 267:518-22

Chang M, Ohno T, Gondon D et al. Adenovinus-mediated transfer of the herpes simplex virus thymidine kinase gene inhibits vascular smooth muscle proliferation and neointima formation following balloon angioplasty of the rat carotid artery. Mol Med 1995b;1:172-81

Chang M, Barr E, Lu M, Barton K, Leiden J. Adenovirus-mediated over-expression of the cyclin/cyclin-dependant kinase inhibitor, p21 inhibits vascular smooth muscle cell proliferation and neointima formation in the rat carotid artery model of balloon angioplasty. J Clin Invest 1996;96:2260-8

Chen S, Wilson J, Muller D. Adenovirus-mediated gene transfer of soluble vascular cell adhesion molecule to porcine interposition vein grafts. Circulation 1994:89:1922-8
Connolly D. Vascular permeability factor a unique regulator of blood vessel function. J Cell Biochem 1991;47:219-23

Conte M, Birinyi L, Miyata T et al. Efficient repopulation of denuded rabbit arteries with autologous gentically modified endothelial cells. Circulation 1994;23:2161-9

Dichek D, Neville R, Zwiebel J. Freeman S, Leon M, Anderson F. Seeding of intravascular stents with gentically engineered endothelial cells. Circulation 1989;80:1347-53

Ellis S, Roubin G, Wilentz J, Douglas J, King S. Effect of 1824 hour heparin administration for prevention of restenosis after uncomplicated coronary angioplasty. Am Heart J 1989:117:777-82

Engelhardt J, Ye X, Doranz B, Wilson J. Ablation of E2A in recombinant adenoviruses improves transgene persistence and decreases inflammatory response in mouse liver. Proc Nall Acad Sci USA 1994;91:6196-200

European Working Group on Critical Limb Ishemia, and Ischemia. Second European consensus document on chronic critical leg ischemia. Circulation 1991;84(suppl IV):IV-1-IV-6

Feldman L, Steg P, Zheng L et al. Low-efficiency of percutaneous adenovinus-medialed anterial gene transfer in the atherosclerotic rabbit. J Clin Invest 1995;95:2662-71

Felgner P. Particulate systems and polymers for in vitro and in vivo delivery of polynucleotides. Adv Drug Delivery Rev 1990;5:163-87

Felgner P, Ringold G. Cationic liposome-mediated transfection. Nature 1989;337:387-8

Felgner P, Gadek T, Holm M et al. Lipofection: a highly efficient, lipid-mediated DNA-transfection procedure. Proc Nall Acad Sci USA 1987:84:7413-7

Fischman DL, Leon MB. Baim DS et al. A randomizod comparison of coronary stent placement and balloon angioplasty in the treatment of coronary artery disease. (The STRESS trial). N Engl J Med 1994;331:496-501

French B, Mazur W, Ali $\mathbf{N}$ et al. Percutaneous transluminal in vivo gene transfer by recombinant adenovirus in normal porcine coronary arteries, atherosclerotic arteries, and two models of coronary restenosis. Circulation 1994;90: 2402-13

Gellman J, Ezekowitz M, Sarembock I et al. Effect of lovastatin on intimal hyperplasia after balloon angioplasty: a study in an atherosclerotic hypercholesterolemic rabbit. J Am Coll Cardiol 1991;17:251-9

Gerard R, Meidel R. Adenovirus-mediated gene transfer. Trends Cardiovasc Med 1993;3:171-7

Glagov S. Intimal hyperplasia, vascular remodeling, and the restenosis problem. Circulation 1994;89:2888-91

Glagov S, Weisenberg E, Zarins CK, Stankunavicius R, Kolettis GJ. Compensatory enlargement of human atherosclerotic coronary arteries. N Engl J Med 1987;316:1371-5

Grossman M, Raper S, Kozarsky K et al. Successful ex vivo gene therapy directed to liver in a patient with familial hypercholesterolaemia. Nature Genet 1994;6:335-41

Herz I, Gerard R. Adenovirus-mediated transfer of low density lipoprotein receptor gene acutely accelerates cholesterol clearance in normal mice. Proc Natl Acad Sci USA 1993; 90:2812-6

Horwitz M. Adenoviridae and their replication. In: Fields $B N$, Knipe DM et al, eds. Fundamental Virology, 2nd odn. New York: Raven Press, 1991:772-804

Huckle W, Drag M, Acker W et al. Effects of subtype-selective and balanced angiotensin II receptor antagonists in a porcine coronary artery model of vascular restenosis. Circulation 1996;93:1009-19

Indolfi C, Avvedimento E, Rapacciuolo $A$ et al. Inhibition of cellular ras prevents smooth muscle cell proliferation after vascular injury in vivo. Narure Med 1995;1:541-5 
Isner J. Walsh K. Symes J et al. Arterial gene therapy for therapeutic angiogenesis in patients with peripheral artery disease. Circularion 1995:91:2687-92

Kass-Eisler A. Falck-Pedersen E, Alvira $M$ et al. Quantitative determination of adenovirus-mediated gene delivery to ral cardiac myocytes in vitro and in vivo. Proc Natl Acad Sci USA 1993:90:11498-502

Kass-Eisler A, Falck-Pedersen E, Elfenbein D, Alvira M, Buttrick $P$, Leinwand $L$. The impact of developmental stage, route of administration and the immune system on adenovinus-mediated gene transfer. Gene Ther 1994:1:395-402

Kolberg R. Gene transfer virus contaminant linked to monkeys' cancer. J NIH Res 1992:4:43-4

Kozarsky K. Wilson J. Gene therapy: adenovirus vectors. Curr Opin Gen Dev 1993;3:499-503

Landau C. Lange R. Hillis L. Percutaneous transluminal coronary angioplasty. $N$ Engl J Med 1994:330:981-93

Lasic D. Papahadjopoulos D. Liposomes revisited. Science 1995:267:1275-6

Leclenc G. Gal D. Takeshita S. Nikol S, Weir L. Isner J. Percutaneous arterial gene transfer in a rabbit model. Efficiency in normal and balloon-dilated atherosclerotic arteries. J Clin Invest 1992:90:936-44

Lemarchand P. Jaffe H. Danel $C$ et al. Adenovirus-mediated transfer of a recombinant human al-antitrypsin CDNA to human endothelial cells. Proc Nasl Acad Sci USA 1992: 89:6482-6

Lemarchand $\mathbf{P}$, Jones $M$, Yamada I, Crystal R. In vivo gene transfer and expression in normal uninjured blood vessels using replication-deficient recombinant adenovinus vectors. Circ Res 1993:72:1132-8

Leyden H. Gibbons G, Morishita R et al. Gene therapy inhibiting neointimal vascular lesion: in vivo transfer of endothelial cell nitric oxide synthase gene. 1995;92:1137-41

Lynch C. Clowes M, Osborne W, Clowes A, Miller A. Longterm expression of human adenosine deaminase in vascular smooth muscle cells of rats: a model of gene therapy. Proc Nall Acad Sci USA 1992;89:1138-42

MERCATOR Study Group. Does the new angiotensin converting enzyme inhibitor cilazapril prevent restenosis after percutaneous transluminal coronary angioplasty? Results of the mercator study: a multicenter, randomized double-blind placebo controlled trial. Circulation 1992: 86:100-10

Morishita R, Gibbons G, Ellison $\mathbf{K}$ et al. Single intraluminal delivery of antisense cdc2 kinase and proliferating-cell nuclear antigen oligonucleotides results in chronic inhibition of neointimal hyperplasia. Proc Nall Acad Sci USA 1993a;90:8474-8

Morishita R, Gibbons G, Kaneda Y, Ogihara T, Dzau V. Novel and effective gene transfer technique for study of vascular renin angiotensin system. J Clin invest 1993b;91: 2580-5

Morishita R. Gibbons G. Ellison $K$ et al. Intimal hyperplasia after vascular injury is inhibited by antisense cdk 2 kinase oligonucleotides. J Clin Invest 1994;93:1458-64

Muhlhauser J, Merrill M, Pili R et al. VEGF 165 expressed by a replication-deficient recombinant adenovirus vector induces angiogenesis in vivo. Circ Res 1995:77:1077-86

Muller D. Ellis S. Topol E. Colchicine and antineoplastic therapy for the prevention of restenosis after percutaneous coronary interventions. J Am Coll Cardiol 1991;17(Suppl B): 126B-31B

Nabel E, Plautz G, Boyce F, Stanley J, Nabel G. Recombinant gene expression in vivo within endothelial cells of the arterial wall. Science 1989;244:1342-4

Nabel E. Plautz G. Nabel G. Site-specific gene expression in vivo by direct gene transfer into the arterial wall. Science 1990;249:1285-8

Nabel E, Gordon D. Yang $Z$ et al. Gene transfer in vivo with DNA-liposome complexes: lack of autoimmunity and gonadal localization. Hum Gene Ther 1992a;3:649-56

Nabel E, Plautz G, Nabel G. Transduction of a foreign histocompatibility gene into the arterial wall. Proc Natl Acad Sci USA 1992b;89:5157-61

Nabel E. Shum L, Pompili V et al. Direct transfer of transforming growth factor beta 1 gene into arteries stimulates fibrocellular hyperplasia. Proc Natl Acad Sci USA 1993a:90: 10759-63

Nabel E. Yang Z, Liptay S et al. Recombinant platelet-derived growth factor $B$ gene expression in porcine arteries induces intimal hyperplasia in vivo. J Clin Invest 1993b;1993: 1822-9

Nabel E, Yang Z, Plautz G et al. Recombinant fibroblast growth factor-1 promotes intimal hyperplasia and angiogenesis. Nalure 1993c;362:844-6

Nabel E, Pompili V, Plautz G, Nabel G. Gene transfer and vascular disease. Cardiovasc Res 1994;28:445-55

Nabel E, Nabel G. Complex models for the study of gene function in cardiovascular biology. Annu Rev Physiol 1994;56: $741-61$

Nakajima M, Hutchinson $H$, Fujinaga $M$ et al. The angiotensin II type 2 (AT2) receptor antagonizes the growth effects of the ATI receptor: gain-of-functio:l study using gene transfer. Proc Nail Acad Sci USA 1995:92:10663-7

Newman K, Dunn P. Owens J et al. Adenovinus-mediated gene transfer into normal rabbit arteries results in prolonged vascular cell activation, inflammation, and neointimal hyperplasia. J Clin Invest 1995:96:2955-65

Ohno T. Gordon D. San H et al. Gene therapy for vascular smooth muscle cell proliferation after arterial injury. Science 1994;265:781-4

Prince G, Porter D, Jenson A, Horswood R, Chanock R, Ginsberg $H$. Pathogenesis of adenovirus type 5 pnemonia in cotton rats (Sigmodon hipsidus). J Virol 1993;67:101-11

Rade J, Schulick A, Virmani R, Dichek D. Local adenoviralmediated expression of recombinan hindin reduces neointima after arterial injury. Nature Med 1996;2:293-8

Riessen R. Rahimizadeh H, Blessing E. Takeshita S, Barry J, Isner J. Arterial gene transfer using pure DNA applied directly to a hydrogel-coated angioplasty balloon. Hum Gene Ther 1993;4:749-58

Ross R. The pathogenesis of atherosclerosis: a perspective for the 1990 's. Nature 1993;362:801-9

Sahni R, Maniet A, Voci G, Barka V. Prevention of restenosis after successful coronary angioplasty. Am Heart J 1991; 121:1600-8

San H, Yang Z, Pompili V et al. Safety and toxicity of a novel cationic lipid formulation of human gene therapy. Hum Gene Ther 1993;4:781-8

Schulick A, Newman K. Virmani R, Dichek D. In vivo gene transfer into injured carotid arteries. Circulation 1995;91: 2407-14

Schwartz R, Holmes D. Topol E. The restenosis paradigm revisited: an altemative proposal for cellular mechanisms. J Am Coll Cardiol 1992;20:1284-93

Semuys PW, de Jaegere P. Kiemeneij $C$ et al. A comparison of balloon expandable stent implantation with balloon angioplasty in patients with coronary artery disease. (The Benestent study). N Engl J Med 1994;331:489-95

Shi Y, Fard A, Vermani P, Zalewski A. Transgene expression in the coronary circulation: transcatheter gene delivery. Gene Ther 1994;1:408-14

Simari R, San H, Rekhter $M$ et al. Regulation of cellular pro- 
liferation and intimal formation following balloon injury in atherosclerotic rabbit arteries. J Clin Invest 1996;98: 218-39

Simons M. Edelman E, DeKeyser J, Langer R, Rosenberg $\mathbf{R}$. Antisense c-myb oligonucleotides inhibit intimal arterial smooth muscle cell accumulation in vivo. Nature 1992;359: 67-70

Smith K, Galloway K, Kennel W, Ogilvie K, Radatus B. A new nucleoside analog, 9-[(2-hydroxy-1-(hydroxymethyl) ethoxyl]methyl]guanine, highly active in vitro against herpes simplex virus types 1 and 2 . Antimicrob Agents Chemother 1982;22:55-61

Steg P, Feldman L, Scoazec J et al. Arterial gene transfer to rabbit endothelial and smooth muscle cells using percutaneous delivery of an adenoviral vector. Circulation 1994;90: 1648-56

Stephan D, Yang ZY, San $H$ et al. A new cationic liposome DNA complex enhances the efficiency of arterial gene transfer in vivo. Hum Gene Ther 1996;7:1803-12

Stewart M, Plautz G, Buono L et al. Gene transfer in vivo with DNA-liposome complexes: safety and acute toxicity in mice. Hum Gene Ther 1992;3:267-75

Takeshita S, Pu L, Stein L et al. Intramuscular administration of vascular endothelial growth factor induces dose-dependant collateral artery augmentation in a rabbit model of chronic limb ischemia. Circulation 1994;90:11-228-34

Thomton M, Gruntzig A, Hollman J, King S, Douglas J. Coumadin and aspirin in prevention of recurrence after transluminal coronary angioplasty: a randomized trial. Circulation 1984;69:721-7

Villa A, Guzman L, Poptic E et al. Effects of antisense c-myb oligonucleotides on vascular smooth muscle cell proliferation and response to vessel wall injury. Circ Res 1995; 76:505-13

Wagner $\mathbf{R}$. Gene inhibition using antisense oligodeoxynucleotides. Nature 1994;372:333-5

Wilson J. Adenoviruses as gene-delivery vehicles. N Engl J Med 1996;334:1185-7

Wilson J, Birinyi L, Salomon R, Libby P, Callow A, Mulligan R. Implantation of vascular grafts lined with genetically modified endothelial cells. Science 1989;244:1344-6

Yang Y, Nunes F, Berencsi K, Gonczol E, Engelhardt J, Wilson J. Inactivation of E2A in recombinant adenoviruses improves the prospect for gene therapy in cystic fibrosis. Nature Genet 1994;7:362-9

Yang ZY. Simari R. Perkins $N$ et al. Role of the p21 cyclindependant kinase inhibitor in limiting intimal cell proliferation in response to arterial injury. Proc Natl Acad Sci USA 1996;93:7905-10 